\title{
OS ESTUDOS DE CASO DOS INIBIDORES DE APETITE E DA FOSFOETANOLAMINA SINTÉTICA: A FRAGILIZAÇÃO DO PAPEL DA ANVISA*
}

Case studies of appetite suppressant and synthetic phosphoethanolamine: The diminishing role of the Brazilian National Health Surveillance Agency

${ }^{1}$ Pontifícia Universidade Católica de Goiás. Goiânia/GO, Brasil.

Correspondência: Ana Carolina Perdigão Faleiros. E-mail: ana.faleiros@anvisa.gov.br.

\footnotetext{
*Este artigo é resultado de pesquisa realizada no âmbito do Curso de Especialização em Gestão em Controladoria Governamental, sob a orientação do professor César Borges.
}

Recebido em: 04/07/2016. Revisado: 28/10/2016. Aprovado: 04/11/2016. 


\section{RESUMO}

Este artigo trata sobre a fragilização do importante papel da Agência Nacional de Vigilância Sanitária que é de proteção da saúde da população - exercido, principalmente, pela mitigação dos riscos decorrentes do consumo de produtos sujeitos a seu controle, tais como os medicamentos. Essa desvalorização da agência está sendo causada pelas crescentes ameaças as suas competências, em grande parte por decisões do Congresso Nacional movidas por pressões de alguns grupos ou mesmo por comoções sociais iludidas por panaceias. São analisados dois casos emblemáticos: o dos inibidores de apetite e o da fosfoetanolamina sintética (a "pílula do câncer").

\section{Palavras-Chave}

Agência Nacional de Vigilância Sanitária; Fosfoetanolamina Sintética; Inibidores de Apetite; Regulação.

\section{ABSTRACT}

This article deals with the diminishing role of the Brazilian National Health Surveillance Agency, whose main objective is to protect the health of the population, particularly through the mitigation of risks from consumer products, such as medications. This devaluation of the agency is caused by the growing threats to its areas of actuation, largely due to decisions made the Brazilian Congress, which is pressured by some groups, or even social upheaval driven by notions of panaceas. Two emblematic cases are analyzed: appetite suppressants and synthetic phosphoethanolamine.

\section{Keywords}

Appetite Suppressant; Brazilian National Health Surveillance Agency; Regulation; Synthetic Phosphoethanolamine. 


\section{Introdução}

O Congresso Nacional, nos últimos anos, vem interferindo nas competências da Agência Nacional de Vigilância Sanitária (Anvisa). Mesmo o Poder Legislativo federal sendo o responsável por elaborar normas gerais de proteção e defesa da saúde (artigo 24, inciso XII, Constituição Federal de 1988 - CF/88 ${ }^{1}$ ), não cabe a ele usurpar a análise essencialmente técnica da Anvisa sobre registro e controle sanitário dos medicamentos, sob pena de ferir o próprio direito à saúde e a separação dos poderes e, sobretudo, colocar a população em risco.

Este trabalho discorre sobre como essas interferências externas causam a constante fragilização da imagem da Anvisa, órgão que deveria ser valorizado e protegido pelos outros poderes e por outras instituições estatais, e não ameaçada - uma vez que é também parte do Estado, tendo o importante papel de proteger a saúde da população. Serão abordados dois casos emblemáticos de desvalorização das atribuições da agência.

Primeiramente será tratado o caso dos inibidores de apetite, cujo Projeto de Lei n. 2.431/2011 ${ }^{2}$ - posteriormente substituído pelo Projeto de Lei da Câmara n. $61 / 2015^{3}$-buscou anular os efeitos da RDC n. 52/2011 ${ }^{4}$ da Anvisa, que proibia o uso dos anorexígenos (anfepramona, femproporex e mazindol) e restringia o uso da sibutramina. Depois será abordado o caso da fosfoetanolamina sintética, conhecida como "pílula do câncer", muito divulgada pela mídia como sendo uma cura milagrosa para todos os tipos de câncer, embora não haja comprovação para tanto. Sua produção e comercialização foram liberadas pela Lei n. 13.269/2016 5 sem a avaliação pela Anvisa de documentação que atestasse a eficácia e a segurança portanto, sem o registro sanitário obrigatório por força da Lei n. 6.360/1976 .

\footnotetext{
1“Art. 24. [...] XII - previdência social, proteção e defesa da saúde”. BRASIL. Constituição Federal da República do Brasil de 1988. Disponível em: <http://www.planalto.gov.br/ccivil_03/constituicao/ constituicaocompilado.htm>. Acesso em: 18 out. 2016.

${ }^{2}$ BRASIL. Câmara dos Deputados. Projeto de Lei n. 2431/2011. Proíbe a Agência Nacional de Vigilância Sanitária de vetar a produção e comercialização dos anorexígenos: sibutramina, anfepramona, femproporex e mazindol. Set 2011. Disponível em: <http://www.camara.gov.br/proposicoesWeb/fichadetramitacao?idP roposicao=522126>. Acesso em: 16 jun. 2016.

${ }^{3}$ BRASIL. Câmara dos Deputados. Projeto de Lei n. 61/2015. Proíbe divulgação na imprensa dos nomes de devedores inadimplentes, antes de sentença judicial e dá outras providências. Disponível em: <http://www. camara.gov.br/proposicoesWeb/fichadetramitacao?idProposicao=944345>. Acesso em: 31 maio 2017. ${ }^{4}$ AGÊNCIA NACIONAL DE VIGILÂNCIA SANITÁRIA. Resolução da Diretoria Colegiada n. 52, de 6 de outubro de 2011. Dispõe sobre a proibição do uso das substâncias anfepramona, femproporex e mazindol, seus sais e isômeros, bem como intermediários e medidas de controle da prescrição e dispensação de medicamentos que contenham a substância sibutramina, seus sais e isômeros, bem como intermediários e dá outras providências. Disponível em: <http://www.anvisa.gov.br/hotsite/anorexigenos/pdf/RDC\%2052-2011\%20 DOU\%2010\%20de\%20outubro\%20de\%202011.pdf>. Acesso em: 18 out. 2016.

${ }^{5}$ BRASIL. Lei n. 13.269, de 13 de abril de 2016. Autoriza o uso da fosfoetanolamina sintética por pacientes diagnosticados com neoplasia maligna. Disponível em: <http://www.planalto.gov.br/ccivil_03/_ato20152018/2016/lei/L13269.htm>. Acesso em: 31 maio 2017.

${ }^{6}$ BRASIL. Lei n. 6.360, de 23 de setembro de 1976. Dispõe sobre a Vigilância Sanitária a que ficam sujeitos os Medicamentos, as Drogas, os Insumos Farmacêuticos e Correlatos, Cosméticos, Saneantes e Outros Produtos, e dá outras Providências. Disponível em: <http://www.planalto.gov.br/ccivil_03/leis/L6360. htm>. Acesso em: 31 maio 2017.
} 


\section{A importância da Anvisa na proteção da saúde}

$\mathrm{Na} \mathrm{CF} / 88$, a saúde passa a ser um direito fundamental, inserido no rol dos direitos sociais do artigo $6^{\circ}$, sendo de índole positiva - ou seja, exige uma atuação concreta do Estado, por meio da implementação de políticas públicas. Estas buscam reduzir os riscos de doenças e agravos e promover o acesso universal e igualitário às ações e aos serviços de saúde, conforme discorre o artigo 196 da CF/88:

Art. $6^{\circ}$ São direitos sociais a educação, a saúde, a alimentação, o trabalho, a moradia, o lazer, a segurança, a previdência social, a proteção à maternidade e à infância, a assistência aos desamparados, na forma desta Constituição.

Art. 196. A saúde é direito de todos e dever do Estado, garantido mediante políticas sociais e econômicas que visem à redução do risco de doença e de outros agravos e ao acesso universal e igualitário às ações e serviços para sua promoção, proteção e recuperação $0^{7}$. (Destaques nossos.)

O Sistema Único de Saúde (SUS) foi criado pela CF/88 para ser um sistema abrangente e universal de acesso à saúde, visando à recuperação, proteção e promoção da saúde. Em seu artigo 200, a CF/88 estabelece as atribuições do SUS, dentre as quais estão o controle e a fiscalização de substâncias de interesse para saúde (inciso I), bem como as funções de prevenção, sendo que o braço do SUS para exercê-las é a vigilância sanitária.

Art. 200. Ao sistema único de saúde compete, além de outras atribuições, nos termos da lei:

I - controlar e fiscalizar procedimentos, produtos e substâncias de interesse para a saúde e participar da produção de medicamentos, equipamentos, imunobiológicos, hemoderivados e outros insumos ${ }^{8}[\ldots]$; (Destaques nossos.)

A Lei Orgânica da Saúde - Lei n. 8.080/1990, uma das leis que regulamenta o SUS - estabelece a vigilância sanitária como campo de atuação do SUS e a define, em seu artigo $6^{\circ}$ parágrafo $1^{\circ}$, como: “conjunto de ações capaz de eliminar, diminuir ou prevenir riscos à saúde e de intervir nos problemas sanitários decorrentes do meio ambiente, da produção e circulação de bens e da prestação de serviços de interesse da saúde"’. (Destaques nossos.)

\footnotetext{
${ }^{7}$ BRASIL. Constituição Federal da República do Brasil de 1988, cit. ${ }^{8}$ Id. Ibid.

${ }^{9}$ BRASIL. Lei n. 8.080/90, de 19 de setembro de 1990. Dispõe sobre as condições para a promoção, proteção e recuperação da saúde, a organização e o funcionamento dos serviços correspondentes e dá outras providências. Disponível em: <http://www.planalto.gov.br/ccivil_03/leis/L8080.htm>. Acesso em: 31 maio 2017.
} 
A Lei n. 9.782/1999 10 criou a Anvisa e o Sistema Nacional de Vigilância Sanitária (SNVS), coordenado por ela. A edição dessa lei foi fundamental para fortalecer a vigilância sanitária no Brasil e, por consequência, o SUS. A Anvisa foi constituída na forma de agência reguladora, autarquia sob regime especial, sendo apenas vinculada ao Ministério da Saúde. É alicerçada sobre três importantes pilares: independência administrativa, estabilidade de seus dirigentes e autonomia financeira.

A grandeza da finalidade institucional da Anvisa foi definida pelo o artigo $6^{\circ}$ da Lei n. 9.782/1999:

[...] promover a proteção da saúde da população, por intermédio do controle sanitário da produção e da comercialização de produtos e serviços submetidos à vigilância sanitária, inclusive dos ambientes, dos processos, dos insumos e das tecnologias a eles relacionados, bem como o controle de portos, aeroportos e de fronteiras ${ }^{11}$. (Destaques nossos.)

Para Almeida e Xavier ${ }^{12}$, assim como as demais agências reguladoras criadas nos meados dos 1990 no âmbito do programa nacional de desestatização e do modelo gerencial de Administração Pública, a Anvisa obteve poderes de regular, controlar e fiscalizar as atividades correlatas a sua área de atuação, assim como dispõe o artigo $8^{\circ}$ da Lei n. 9.782/1999 "Incumbe à Agência, respeitada a legislação em vigor, regulamentar, controlar e fiscalizar os produtos e serviços que envolvam risco à saúde pública"13. (Destaques nossos.)

Dentre as prerrogativas garantidas às agências reguladoras, o poder de polícia e o poder regulatório são as principais. Ambas as prerrogativas foram concedidas às agências a fim de lhes assegurar uma atuação independente, livre de pressões externas indevidas, para que suas decisões fossem fundamentadas essencialmente em conhecimento técnico-científico.

O poder de polícia permite ao Estado limitar o exercício dos direitos individuais em prol do interesse público. No caso da Anvisa, como seu objetivo é proteger a saúde da população, cabe a ela exercer ações de caráter preventivo ou coercitivo, visando à segurança sanitária em benefício da coletividade. A partir dessa prerrogativa, a Anvisa pode retirar do mercado um produto para proteger a população

\footnotetext{
${ }^{10}$ BRASIL. Lei n. 9.782, de 26 de janeiro de 1999. Define o Sistema Nacional de Vigilância Sanitária, cria a Agência Nacional de Vigilância Sanitária, e dá outras providências. Disponível em: <http://www.planalto. gov.br/ccivil_03/leis/L9782.htm>. Acesso em: 18 out. 2016.

${ }^{11}$ Id. Ibid.

${ }^{12}$ ALMEIDA, E. S.; XAVIER, E. D. O poder normativo e regulador das agências reguladoras federais: abrangência e limites. Âmbito Jurídico, Rio Grande, v. 15, n. 98, mar. 2012. Disponível em: <http:// www.ambitojuridico.com.br/site/?artigo_id=11293\&n_link=revista_artigos_leitura>. Acesso em: 15 jun. 2016.

${ }^{13}$ BRASIL. Lei n. 9.782, de 26 de janeiro de 1999, cit.
} 
dos riscos provenientes de seu uso, mesmo que muitos particulares frequentemente o consumam.

De acordo com Costa $^{14}$, o poder regulatório da Anvisa a coloca como um mediador entre mercado e consumidor. O exercício desse poder se dá em grande parte por meio do poder normativo, ao se estabelecerem regras a fim de harmonizar essa relação. Para tanto, as normas elaboradas pela agência devem estar fundamentadas na legislação vigente, não podendo inovar ordenamento jurídico nem contrariá-lo. Tais normas são importantes para melhor aplicação das leis, por pormenorizarem seus ditames. Nos incisos III e IV do artigo $7^{\circ}$, e no $\$ 4^{\circ}$ do artigo $8^{\circ}$ da Lei n. 9.782/1999, fica claro o poder normativo da Anvisa em seu âmbito de atuação:

III - estabelecer normas, propor, acompanhar e executar as políticas, as diretrizes e as ações de vigilância sanitária;

IV - estabelecer normas e padrões sobre limites de contaminantes, resíduos tóxicos, desinfetantes, metais pesados e outros que envolvam risco à saúde ${ }^{15}$;

$\S 4^{\circ}$ A Agência poderá regulamentar outros produtos e serviços de interesse para o controle de riscos à saúde da população, alcançados pelo Sistema Nacional de Vigilância Sanitária ${ }^{16}$.

As Resoluções de Diretoria Colegiada (RDCs) são os atos normativos mais comuns da Anvisa; expressam a decisão do colegiado da agência, composto de cinco diretores. As RDCs preveem sanções para quem as descumprir, sendo, portanto, de caráter obrigatório às empresas responsáveis por produtos ou serviços sujeitos à vigilância sanitária - comumente denominadas de "setor regulado". Quando a Diretoria Colegiada julgar relevante, pode fazer uma consulta pública, que consiste em dar oportunidade para o setor regulado e demais interessados opinarem e, talvez, alterarem uma RDC antes de sua vigência, de seus impactos ${ }^{17}$.

As competências da Anvisa presentes nos incisos XV e IX do artigo $7^{\circ}$ da Lei n. 9.782/1999 são as mais importantes para este trabalho. No caso dos anorexígenos, a Anvisa utilizou-se de sua competência de proibi-los (inciso XV) por entender se tratar de risco iminente à saúde, dado que os danos superavam os benefícios. Já no caso da fosfoetanolamina sintética, a Anvisa não analisou a documentação

\footnotetext{
${ }^{14}$ COSTA, E. A. Regulação e vigilância sanitária para a proteção da saúde. In: Vieira, F. P.; Rediguieri, C. F.; Rediguieri, C. F. (Orgs.). A regulação de medicamentos no Brasil. Porto Alegre: Artmed, 2013. p. 21-37. ${ }^{15}$ BRASIL. Lei n. 9.782, de 26 de janeiro de 1999, cit.

${ }^{16}$ Id. Ibid.

${ }^{17}$ AGÊNCIA NACIONAL DE VIGILÂNCIA SANITÁRIA. Resolução da Diretoria Colegiada-RDC n. 61, de 3 de fevereiro 2016. Aprova e promulga o Regimento Interno da Agência Nacional de Vigilância Sanitária - ANVISA e dá outras providências.. Disponível em: <http://portal.anvisa.gov.br/documents/281258/281284/RD C\%2BN\%2B61\%2BRegimento\%2BAnvisa.pdf/07ccbb20-f3b3-4209-bf84-f520a1a29eab>. Acesso em: 31 maio 2017.
} 
comprobatória de eficácia e segurança, pré-requisito para o registro sanitário, pois não fora protocolada na agência nenhuma solicitação nesse sentido - mesmo porque ainda não havia estudos suficientes para tanto.

IX - conceder registros de produtos, segundo as normas de sua área de atuação;

XV - proibir a fabricação, a importação, o armazenamento, a distribuição e a comercialização de produtos e insumos, em caso de violação da legislação pertinente ou de risco iminente à saúde ${ }^{18} ;[\ldots]$ (Destaques nossos.)

\section{0 caso dos inibidores de apetite}

Em outubro 2010, a Câmara Técnica de Medicamentos (Cateme), uma instância consultiva, sugeriu à Anvisa a retirada dos inibidores de apetite do mercado, afirmando a inexistência de evidências científicas que comprovassem a eficácia e a segurança desses medicamentos: anfepramona, femproporex, mazindol e sibutramina. Havia fortes evidências de que o risco superava o benefício, não sustentando mais a permanência dessas substâncias no mercado nacional. Inclusive, o uso desses medicamentos estava fortemente relacionado ao risco de problemas cardíacos. Por isso, a Anvisa divulgou no início de 2011 uma nota técnica para esclarecer os motivos pelos quais pretendia tirá-los do mercado ${ }^{19}$.

Nessa nota técnica, a Anvisa ressaltou que, devido a seu poder regulador, poderia rever periodicamente os produtos disponíveis no mercado, a fim de reduzir o risco inerente às propriedades farmacológicas e toxicológicas dos medicamentos. Portanto, caberia revisar o perfil de segurança e eficácia desses produtos. Destacou que, até aquele momento, não havia a constatação de eficácia e segurança dos inibidores de apetite, especialmente quando se avaliavam os efeitos de longo prazo desses medicamentos no controle da obesidade.

Na nota técnica, ficou evidente que a Anvisa seguia uma tendência internacional, já que países europeus não utilizavam mais a anfepramona, o femproporex e o mazindol como anorexígenos desde 1999. A Europa não possuía mais a sibutramina em seu mercado desde janeiro de 2010, e os Estados Unidos já tinham cancelado seu registro em outubro de 2010. Enquanto isso, no Brasil, o consumo dos inibidores de apetite era irracional e elevadíssimo, bem acima do preconizado pela Organização Mundial da Saúde e seus órgãos sanitários. A dimensão do exagero era percebida pelos dados: entre 1998 e 2005, houve um

\footnotetext{
${ }^{18}$ BRASIL. Lei n. 9.782, de 26 de janeiro de 1999, cit.

${ }^{19}$ AGÊNCIA NACIONAL DE VIGILÂNCIA SANITÁRIA. Nota Técnica sobre a eficácia e segurança dos medicamentos inibidores de apetite. Brasília, 2011. Disponível em: <http://www.anvisa.gov.br/hotsite/ anorexigenos/pdf/Nota_Tecnica_Anorexigenos.pdf>. Acesso em: 16 jun. 2016.
} 
aumento de cerca de $500 \%$ no consumo de anorexígenos; em 2010, foram prescritas 4,4 milhões de receitas ${ }^{20,21}$.

Dados do Sistema Nacional de Gerenciamento de Produtos Controlados (SNGPC) mostravam que, entre os dez maiores prescritores de anfepramona, estavam um ginecologista e um gastroenterologista; o maior prescritor de femproporex era um dermatologista; e, entre os dez que mais receitam mazindol, havia um pediatra. Segundo Relatório Final da Comissão de Seguridade Social e Família, que acompanhou a nota técnica da Anvisa à época, outra informação chama a atenção:

Entre os dez maiores prescritores de medicamentos em 2009 e 2010 para o uso de femproporex, houve considerável aviamento de receita por parte de pediatras - sendo que o medicamento não é indicado para menores de 18 anos. Já a medicina do tráfego aparece como um dos dez maiores prescritores da sibutramina ${ }^{22}$.

Esses dados coadunam que médicos que não eram endocrinologistas - portanto, não acompanhavam os pacientes obesos - eram os que mais prescreviam. Para muitos médicos, o maior controle da dispensação dos anorexígenos - imposto pela Anvisa em março de 2010 com a exigência de receita de controle especial - já era suficiente para controlar o exagero na prescrição desses medicamentos. Além disso, a proposta de retirada dos inibidores de apetite do mercado não agradava as associações médicas, o Conselho Federal de Medicina (CFM), os representantes das farmácias de manipulação (responsáveis por $80 \%$ das receitas aviadas), entre outros, que alegavam que isso seria um abuso de poder da Anvisa, uma restrição às opções de tratamento da obesidade e uma lesão à soberania da clínica ${ }^{23,24}$.

Em fevereiro de 2011, a Anvisa realizou uma audiência pública em seu auditório para apresentar uma argumentação técnico-científica relacionada com questões de eficácia e segurança dos medicamentos inibidores de apetite registrados no Brasil. Nessa audiência, o corpo técnico da Anvisa ouviu diversas opiniões e contra-argumentações, dando espaço para um amplo debate sobre o tema. O evento

\footnotetext{
${ }^{20}$ BRASIL. Câmara dos Deputados. Comissão de Seguridade Social e Família. Relatório final do Grupo de Trabalho destinado a acompanhar e discutir a Nota Técnica da Anvisa, que prevê o banimento dos medicamentos inibidores de apetite. Brasília, nov. 2011. Disponível em: <http://www2.camara.leg.br/ atividade-legislativa/comissoes/comissoes-permanentes/cssf/documentos-1/relatorios-2/relatorio-dogrupo-de-trabalho-medicamentos-inibidores-de-apetite>. Acesso em: 25 jun. 2016.

${ }^{21}$ LUCCHESE, Geraldo. Projeto de Lei n. 2.431, de 2011, e a regulação dos anorexígenos no Brasil. Escola Nacional de Saúde Pública Sérgio Arouca - Fundação Oswaldo Cruz, 2013. Disponível em: <http://www6. ensp.fiocruz.br/visa/?q=node/5910>Acesso em: 25 jun. 2016.

${ }^{22}$ BRASIL. Câmara dos Deputados. Comissão de Seguridade Social e Família. Relatório final do Grupo de Trabalho destinado a acompanhar e discutir a Nota Técnica da Anvisa, que prevê o banimento dos medicamentos inibidores de apetite, cit.

${ }^{23}$ Id. Ibid.

${ }^{24}$ LUCCHESE, Geraldo. op. cit.
} 
contou com a presença de 300 inscritos, entre médicos, membros da comunidade científica, sociedade civil, representantes do Poder Judiciário e imprensa ${ }^{25}$.

Após muitas discussões sobre o tema, a Diretoria Colegiada da Anvisa decidiu que inibidores de apetite do tipo anfetamínico seriam retirados do mercado e que a sibutramina permaneceria, mas sob novas restrições - amenizando a proposta inicial, que era de também proibi-la. A partir dessa decisão, femproporex, mazindol e anfepramona tiveram seus registros cancelados, sendo proibidos a produção, o comércio, a manipulação e o uso desses produtos com a justificativa de que seu uso estava baseado na prática clínica apenas, sem que houvesse evidências suficientes para sustentar os padrões de exigência de registro de medicamentos então em vigor $^{26}$. Além disso, havia comprovação de eventos adversos graves e ausência de dados confiáveis de segurança.

Já em relação à sibutramina, sua manutenção no mercado foi possível porque seu perfil de segurança era bem definido, permitindo identificar pacientes que podiam ter algum benefício a partir de seu uso. Uma das restrições para essa substância foi que a descontinuidade em pacientes que não tivessem resultados após quatro semanas de uso ${ }^{27}$.

Diante dessa decisão, a RDC n. 52/2011 ${ }^{28}$ foi publicada em outubro de 2011. Esta RDC proibiu a fabricação, a importação, a comercialização, a prescrição, a dispensação e o aviamento dos anorexígenos anfepramona, femproporex e mazindol, e submeteu a prescrição da sibutramina a controles mais restritos. No entanto, sob fortíssimo lobby das entidades e deputados médicos e farmacêuticos, surgiu o Projeto de Lei n. 2.431/2011 ${ }^{29}$, de autoria do deputado Felipe Bornier (PROS-RJ), que busca anular os efeitos da RDC n. 52/2011 e, consequentemente, é uma afronta ao poder regulatório da Anvisa. O artigo $1^{\circ}$ desse PL tem uma redação extremamente abusiva ${ }^{30}$ :

Art. $1^{\circ}$ Fica a Agência Nacional de Vigilância Sanitária proibida de cancelar o registro sanitário ou de adotar qualquer outra medida que impeça a produção ou a comercialização dos anorexígenos: sibutramina, anfepramona, femproporex e mazindol ${ }^{31}$. (Destaques nossos.)

\footnotetext{
${ }^{25}$ BRASIL. Câmara dos Deputados. Comissão de Seguridade Social e Família. Relatório final do Grupo de Trabalho destinado a acompanhar e discutir a Nota Técnica da Anvisa, que prevê o banimento dos medicamentos inibidores de apetite, cit.

${ }^{26}$ Id. Ibid.

${ }^{27}$ Id. Ibid.

${ }^{28}$ AGÊNCIA NACIONAL DE VIGILÂNCIA SANITÁRIA. Resolução da Diretoria Colegiada n. 52, de 6 de outubro de 2011, cit.

${ }^{29}$ BRASIL. Câmara dos Deputados. Projeto de Lei n. 2431/2011, cit.

${ }^{30}$ ASSOCIAÇÃO BRASILEIRA DE SAÚDE COLETIVA. Carta Aberta ao Congresso Nacional contra a aprovação do projeto de Lei $n^{\circ}$ 2.431/2011. A regulação dos anorexígenos no Brasil. dez 2013. Disponível em: <https:// www.abrasco.org.br/site/2013/12/carta-aberta-ao-congresso-nacional-contra-a-aprovacao-do-projeto-delei-no-2-4312011-a-regulacao-dos-anorexigenos-no-brasil/>. Acesso em: 20 jun. 2016.

${ }^{31}$ BRASIL. Câmara dos Deputados. Projeto de Lei n. 2431/2011, cit.
} 
Esse projeto entrou recentemente - junho de 2016 - em regime de urgência na Câmara dos Deputados, a pedido do deputado Ronaldo Fonseca (PROS-DF). $\mathrm{O}$ autor do PL, Felipe Bornier, defende a aprovação sob o seguinte argumento: "Esses medicamentos vinham sendo comercializados há mais de 50 anos no Brasil. E não sei por que de uma hora para outra a Anvisa decidiu proibir o uso dessas substâncias. Precisamos dar uma resposta à população brasileira que depende do uso desses medicamentos". Contrária a ele, a deputada Erika Kokay (PT-DF) defendeu a atuação da Anvisa: "Os medicamentos devem ser analisados pelas câmaras técnicas da Anvisa. Não podemos aprovar uma legislação que proíbe a Anvisa de proibir, que é sua função principal: regular o uso de substâncias" ${ }^{32}$. (Destaques Nossos.)

Segundo a Associação Brasileira de Saúde Coletiva (Abrasco), o PL n. 2.431/2011 afronta o artigo 200 da CF/88, que dá competência ao SUS para realizar a vigilância sanitária, incluindo o controle sanitário dos medicamentos. Para essa entidade, o PL foi uma decisão de natureza política, fundamentada em interesses específicos, passando por cima de decisão técnica moldada pelo interesse da saúde pública ${ }^{33}$.

Em setembro de 2014, o Projeto de Decreto Legislativo (PDC) n. 1.123/2013 ${ }^{34}$ sustou a RDC n. 52/2011 na íntegra, buscando a liberação da venda dos inibidores de apetite. A Anvisa reagiu e, no mesmo mês, publicou a RDC n. 50/2014 ${ }^{35}$, autorizando a produção industrial dessas substâncias e definindo normas para comercialização e controle, como: retenção de receita, assinatura de termo de responsabilidade pelo médico e termo de consentimento pelo usuário, assim como já ocorria no caso da sibutramina ${ }^{36}$.

\footnotetext{
${ }^{32}$ CÂMARA aprova urgência para projeto que ratifica liberação de inibidores de apetite. Resolução da Anvisa que proibia a venda desses medicamentos já foi derrubada pelo Congresso em 2014. Câmara Notícias, Brasília, 14 jun. 2016. Disponível em: <http://www2.camara.leg.br/camaranoticias/noticias/ SAUDE/510594-CAMARA-APROVA-URGENCIA-PARA-PROJETO-QUE-RATIFICA-LIBERACAO-DE-INIBIDORESDE-APETITE.html>Acesso em: 25 jun. 2016.

${ }^{33}$ ASSOCIAÇÃO BRASILEIRA DE SAÚDE COLETIVA. Carta Aberta ao Congresso Nacional contra a aprovação do projeto de Lei $n^{\circ} 2.431 / 2011$. A regulação dos anorexígenos no Brasil, cit.

${ }^{34}$ BRASIL. Câmara dos Deputados. Projeto de Decreto Legislativo n. 1.123/2011. Lei n. 2431/201. Susta a Resolução - RDC n. 52/2011, de 6 de outubro de 2011, da Agência Nacional de Vigilância Sanitária (Anvisa), que “Dispõe sobre a proibição do uso das substâncias anfepramona, femproporex e mazindol, seus sais e isômeros, bem como intermediários e medidas de controle da prescrição e dispensação de medicamentos que contenham a substância sibutramina, seus sais e isômeros, bem como intermediários e dá outras providências". Disponível em: <http://www.camara.gov.br/proposicoesWeb/fichadetramitacao ?idProposicao=586952>. Acesso em: 31 maio 2017.

${ }^{35}$ AGÊNCIA NACIONAL DE VIGILÂNCIA SANITÁRIA. Resolução da Diretoria Colegiada n. 50, de 25 de setembro de 2014. Dispõe sobre as medidas de controle de comercialização, prescrição e dispensação de medicamentos que contenham as substâncias anfepramona, femproporex, mazindol e sibutramina, seus sais e isômeros, bem como intermediários e dá outras providências. Disponível em: <http://portal. anvisa.gov.br/documents/33880/2568070/reprdc0050_25_09_2014.pdf/d04dec76-4dbb-4d04-a72150bd191a1a9b?version=1.0>. Acesso em: 31 maio 2017.

${ }^{36}$ ANVISA requer novo registro para comercialização de mazindol, femproporex e anfepramona. Notícias, Conselho Regional de Farmácia de Estado de São Paulo - CRF SP, São Paulo, 26 set. 2014. Disponível em: <http://portal.crfsp.org.br/index.php/noticias/5862-rdc-50-14.html>. Acesso em: 26 jun. 2016.
} 
No entanto, os interessados em fabricar os anfetamínicos mazindol, femproporex e anfepramona, segundo a nova resolução, necessitariam de novo registro que comprovasse a eficácia e segurança novamente, sendo inaceitável apenas o argumento de permanência no mercado nacional por diversos anos. Embora necessária, essa rigidez impossibilitou a volta desses medicamentos ao mercado, uma vez que deveriam esperar muito tempo para conseguir seu registro novamente, mesmo se tivessem como comprovar o que a Anvisa exigia ${ }^{37}$.

Outra restrição trazida pela RDC n. 50/2014 é que as farmácias de manipulação, desde então, só estão autorizadas a fabricar medicamentos quando houver novamente o registro na Anvisa do respectivo produto industrial contendo as substâncias anorexígenas. Após concedido o registro, a comercialização tanto dos medicamentos industrializados como dos manipulados passou a ser controlada, como ocorria anteriormente com a sibutramina. Como a produção industrial e a manipulação da sibutramina continuaram permitidas e o controle permaneceu o mesmo, não ocorreram mudanças na regulação dessa substância ${ }^{39}$.

Para a Abrasco, o PDC n. 1.123/2013 é uma nova tentativa de desautorizar uma decisão legítima da Anvisa. Segundo a associação, trata-se de um projeto flagrantemente inconstitucional e é lamentável que tenha ocorrido a aprovação de matéria tão nociva à saúde coletiva, realizando um intervenção "equivocada e estapafúrdia" sobre a competência e a autoridade sanitária da Anvisa. A entidade acredita que esse fato deixou claro que em nosso país ainda predominam os interesses particulares sobre os coletivos. Repudiou o PDC, enumerando duas justificativas:

I) afronta o Estado de Direito, uma vez que a Anvisa agiu estritamente dentro de suas competências legais previstas na Lei $\mathrm{n}^{\circ} 9.782$, de 1999 , em seu art. $6^{\circ}$; no art. $7^{\circ}$, inciso XV; e, principalmente no art. $8^{\circ}$, inciso I;

II) afronta elementares princípios de segurança e eficácia dos medicamentos, uma vez que as substâncias anfepramona, femproporex e mazindol produzem efeitos circunstanciais de controle da fome, são efetivamente causadores de dependência, promovem sérios efeitos adversos, tais como taquicardia, euforia, depressão, perturbação mental e infarto e jamais tiveram estudos de risco-benefício demonstrados e aprovados ${ }^{40}$. (Destaques nossos.)

\footnotetext{
${ }^{37}$ ANVISA requer novo registro para comercialização de mazindol, femproporex e anfepramona, cit.

${ }^{38}$ AGÊNCIA NACIONAL DE VIGILÂNCIA SANITÁRIA. Resolução da Diretoria Colegiada n. 50, de 25 de setembro de 2014 , cit.

${ }^{39}$ ld. Ibid.

${ }^{40}$ DIAS, Bruno C. Decreto aprovado pela Câmara dos Deputados libera venda e produção de anorexígenos. ABRASCO. Associação Brasileira de Saúde Coletiva, 09 abr. 2014. Disponível em: <https://www. abrasco.org.br/site/2014/04/decreto-aprovado-pela-camara-dos-deputados-libera-venda-e-producao-deanorexigenos-coordenacao-do-gt-visa-lanca-nota-de-repudio/>. Acesso em: 24 jun. 2016.
} 
Na opinião de Geraldo Lucchese, coordenador do Grupo Temático Vigilância Sanitária da Abrasco (GT-VISA), as entidades da saúde e de direitos do consumidor não deveriam ficar caladas: "O momento é de organizar a sociedade civil para pressionar o Senado e cobrar do Ministério da Saúde um posicionamento de defesa de sua agência de vigilância sanitária”. Segundo ele, outra ação possível seria o ingresso de uma Ação de Inconstitucionalidade no Supremo ${ }^{41}$.

Mesmo após a RDC n. 50/2014, o deputado Felipe Bornier (PSD-RJ) apresentou o projeto PLC n. 61/2015 - originado do PL n. 2.431/2011, também de sua autoria -, cuja redação difere um pouco do PL anterior: ao invés de proibir a Anvisa de proibir a produção e a comercialização dos anorexígenos, esse PLC autoriza a produção, a comercialização e o consumo, sob prescrição médica, dos inibidores de apetite.

Em fevereiro de 2016, o PLC n. 61/2015 teve parecer favorável da Comissão de Meio Ambiente, Defesa do Consumidor e Fiscalização e Controle do Senado Federal, sob os argumentos de senadores como Otto Alencar (PSD-BA) e Ronaldo Caiado (DEM-GO), de que a proibição desses produtos prejudicava milhares de pacientes que necessitavam desses medicamentos e de que isso provocaria a ampliação do mercado clandestino. Para Ronaldo Caiado (DEM-GO), os médicos, e não a Anvisa, têm conhecimento e prerrogativa de decidir se seus pacientes devem ou não continuar a utilizar os medicamentos à base dessas substâncias, já que estas se encontram há tantos anos no mercado brasileiro ${ }^{42}$.

Em junho de 2016, o Senado Federal aprovou o PLC n. 61/2015 com alterações, devendo o projeto voltar para a Câmara dos Deputados. A senadora Vanessa Grazziotin (PCdoB-AM) havia apresentado emenda ao projeto, mas essa foi rejeitada. Para a senadora, as normas sanitárias vigentes deveriam ser observadas, sob o temor de que esse projeto de lei abra caminho para a retirada da obrigatoriedade de registro de outros produtos. Segundo o bom senso da referida senadora, é arriscado dar autorização automática sem passar pela vigilância sanitária ${ }^{43}$.

Em reação à aprovação do PLC n. 61/2015 pelo Senado, a Anvisa divulgou nota em seu site na internet expondo sua preocupação quanto aos impactos dessa medida sobre a saúde da população brasileira. Esclareceu que, como consequência da liberação de produtos que contenham as substâncias sibutramina, anfepramona, femproporex e mazindol, o controle e a fiscalização desses medicamentos ficarão praticamente inexistentes. Além disso, os riscos de efeitos adversos aumentam,

\footnotetext{
${ }^{41}$ DIAS, Bruno C. op. cit.

${ }^{42}$ BRASIL. Senado Federal. Comissões. 16 fev. 2016. Disponível em: <http://www12.senado.leg.br/noticias/ materias/2016/02/16/venda-de-remedios-para-emagrecer-pode-ser-autorizada-por-lei/tablet>. Acesso em: 26 jun. 2016.

${ }^{43}$ Id. Ibid.
} 
já que não há comprovação científica satisfatória de eficácia e segurança, além de não haver relação risco-benefício justificável ${ }^{44}$.

A Anvisa reforçou a tese do presente trabalho, afirmando que, com este PLC, o Senado e, anteriormente, a Câmara afrontam a Lei n. 9.782/199945, que incumbe à Anvisa a responsabilidade do controle sanitário de medicamentos, sendo que a agência pode proibir a fabricação, a importação, o armazenamento, a distribuição e a comercialização de produtos e insumos em caso de risco iminente à saúde. Destacou ainda que a RDC n. 50/14 já tinha normatizado a produção, a venda e o consumo de anorexígenos, determinando, entre outros pontos, doses recomendadas, prescrições acompanhadas de termo de responsabilidade do médico responsável e relatórios periódicos sobre as substâncias por parte das empresas produtoras ${ }^{46}$.

Antes do caso dos anorexígenos, já tinham ocorrido ações no sentido de desautorizar o poder regulatório da Anvisa, como nos casos de interferências na regulação do tabaco e da propaganda de alimentos voltada para o público infantil. Com base nesse histórico, o Centro Colaborador em Vigilância Sanitária (Cecovisa), da Escola Nacional de Saúde Pública Sergio Arouca da Fundação Oswaldo Cruz (Ensp/Fiocruz), fez um questionamento, em entrevista realizada em junho de 2014, ao ex-ministro da Saúde e ex-diretor da Anvisa José Agenor Álvares da Silva:

Cecovisa - O Congresso Nacional tem revogado e dificultado algumas ações restritivas da Anvisa. O caso dos anorexígenos, do tabaco e da propaganda de alimentos voltada para o público infantil são exemplos. $\mathrm{O}$ que estaria por trás desses episódios e quais seus efeitos para a Agência e a Saúde da população ${ }^{47}$

Álvares da Silva respondeu que a motivação legislativa de revogar decisões da Agência, ao invés de se respaldar na saúde pública, baseia-se exclusivamente nos interesses de certos setores corporativos e industriais. Segundo ele, esse conflito do poder regulatório da Anvisa com o entendimento do Legislativo é uma contrarregulação, uma tentativa de esvaziar a competência não só da Anvisa, como de todas as agências reguladoras ${ }^{48}$.

${ }^{44}$ ANOREXÍGENOS: posição da Anvisa sobre o PLC 61/15. Agência Nacional de Vigilância Sanitária., 22 abr. 2016. Disponível em: <http://portal.anvisa.gov.br/noticias?p_p_id=101_INSTANCE_ FXrpx9qY7FbU\&p_p_col_id =column2\&p_p_col_pos $=1 \&$ p_p_col_count $=2 \&$ \&_101_INSTANCE_ FXrpx9qY7FbU_groupld=219201\&_101_INSTANCE_FXrpx9qY7FbU_urlTitle=anvisa-manifestapreocupacao-pelos-possiveis-resultados-da-aprovacao-do-plc-61-15\&_101_INSTANCE_FXrpx9qY7FbU_ struts_action $=\% 2$ Fasset_publisher\%2Fview_content\&_101_INSTANCE_FXrpx9qY7FbU_ assetEntryld=2657060\&_101_INSTANCE_FXrpx9qY7FbU_type=content>. Acesso em: 28 jun. 2016.

${ }^{45}$ BRASIL. Lei n. 9.782, de 26 de janeiro de 1999, cit.

${ }^{46}$ ANOREXÍGENOS: posição da Anvisa sobre o PLC 61/15, cit.

47 “PODEMOS comemorar a inserção da Vigilância Sanitária como uma parte da saúde coletiva”. Entrevistado: José Agenor Álvares da Silva. Escola Nacional de Saúde Pública Sérgio Arouca - Fundação Oswaldo Cruz, 16 jun. 2014. Disponível em: <http://www6.ensp.fiocruz.br/visa/?q=node/6170>. Acesso em: 14 jun. 2016.

${ }^{48}$ Id. Ibid. 
De acordo com Álvares da Silva, o resultado disso é a minoração da credibilidade da agência, nacional e internacionalmente, um verdadeiro retrocesso ao período anterior à criação da Anvisa, quando a vigilância sanitária federal era tida como um verdadeiro balcão de negócios. Para ele, há uma fragilização da competência institucional do aparelho de Estado: assim que a Anvisa regulamenta uma lei, e com isso, fere interesses corporativos fortes, avoca-se uma suposta intromissão nas competências do Congresso e, assim, negam-se as competências inerentes à agência, bem como sua função de proteger a saúde da população ${ }^{49}$.

\section{0 caso da fosfoetanolamina sintética}

A fosfoetanolamina é uma substância produzida pelo corpo humano. Sua versão sintética foi descoberta no final da década de 1980 pelo docente Gilberto Orivaldo Chierice, hoje aposentado, do Instituto de Química de São Carlos (IQSC) da Universidade de São Paulo (USP). Segundo seus estudos, a fosfoetanolamina sintética teve resultado positivo, em altas concentrações, em alguns tipos células tumorais de laboratório e em camundongos com leucemia. Por decisão unicamente pessoal, sem autorização da universidade, o químico distribuiu pílulas contendo essa substância a diversas pessoas com câncer. Muitas delas relataram melhora com o uso da substância, e isso foi ganhando repercussão. Com a grande divulgação na mídia que o caso teve, criou-se uma crença de que essa droga era milagrosa e servia para todos os tipos de câncer ${ }^{50}$.

Há relatos de que, em 2011, o grupo do químico foi procurado por representantes do programa de Desenvolvimento e Inovação de Fármacos Anticâncer do Ministério de Saúde, que buscavam fármacos promissores para tratar a doença. Foi proposto ao grupo refazer a rota de desenvolvimento, segundo critérios nacionais e internacionais, para tornar seu estudo eticamente aceitável, visto que ainda faltava $95 \%$ de desenvolvimento a ser feito - ou seja, anos de pesquisa. Mas os pesquisadores recusaram terminantemente, alegando que já distribuíam gratuitamente as pílulas e que elas funcionavam. Por mais que o grupo acreditasse que os resultados iniciais de seus estudos fossem relevantes, seria preciso mais estudos antes de distribuí-las à população. Essa foi uma atitude imprudente, podendo ser considerada charlatanismo, uma vez que ainda se sabia muito pouco sobre a segurança desse uso ${ }^{51}$.

\footnotetext{
49“PODEMOS comemorar a inserção da Vigilância Sanitária como uma parte da saúde coletiva”, cit.

${ }^{50}$ BRASIL. Ministério da Ciência e Tecnologia. Resumo executivo. Avaliação da atividade citotóxica e antiproliferativa da Fosfoetanolamina, Monoetanolamina e Fosfobisetanolamina em Células Humanas de Carcinoma de Pâncreas e Melanoma. Abr. 2016. Disponível em: <http://www.mcti.gov.br/ documents/10179/1274125/Resumo+executivo+Encomenda+MCTI-CNPq+-+Citoxicidade+celulas+canc eriginas+humanas.pdf/b1acdfa5-4743-4bfe-affa-0e8ca222fad2>. Acesso em: 29 jul. 2016.

${ }^{51}$ FACHIN fala sobre a decisão de liberar a Fosfoetanolamina: "Foi uma exceção." Época, São Paulo, 19 out. 2015. Disponível em: <http://epoca.globo.com/tempo/filtro/noticia/2015/10/fachin-fala-sobre-decisaode-liberar-fosfoetanolamina-foi-uma-excecao.html>. Acesso em: 26 jun. 2016.
} 
A investigação de qualquer droga requer a condução de vários estudos, pré-clínicos (também chamados de não clínicos) e clínicos (em seres humanos). Os ensaios pré-clínicos duram, em média, de três a cinco anos e consistem em estudos in vitro, realizados em células (de animais e humanas), e em in vivo, realizados em animais. Esses ensaios pré-clínicos são destinados a avaliar a atividade farmacológica/terapêutica da droga candidata. Também é necessário analisar a droga quanto a: farmacocinética (absorção, metabolismo, distribuição e eliminação), genotoxicidade, segurança farmacológica e toxicidade de doses repetidas; essas análises não foram conduzidas pelo grupo do químico Chierice. Apenas quando a substância mostra-se promissora, ou seja, com efeito farmacológico/terapêutico suficiente e não tóxico em humanos, é que os ensaios clínicos se iniciam, a fim de avaliar seu comportamento em seres humanos ${ }^{52,53}$.

Os estudos clínicos, realizados em voluntários, são os que mais demandam tempo e recursos, sendo divididos em quatro fases sucessivas. Fase I: o objetivo dessa fase é avaliar a segurança e toxicidade da droga, definindo a forma de administração mais adequada; a maior dose tolerada; a farmacocinética da droga (absorção, distribuição, metabolização, excreção); e se os efeitos colaterais são suportáveis. Essa fase é geralmente realizada com poucos voluntários saudáveis (20 a 100), sendo que para doenças graves, como o câncer, recrutam-se apenas pacientes com a doença, devido à alta toxidade das drogas oncológicas e às questões éticas envolvidas ${ }^{54,55}$.

Fase II: é realizada com um número maior de indivíduos (100 a 200). O objetivo principal é avaliar a eficácia da droga candidata, ou seja, saber se ela realmente funciona. Buscam-se também informações mais detalhadas sobre a segurança do uso da substância (toxicidade). Para avaliar eficácia da droga-teste nos ensaios clínicos em câncer, diversos resultados são almejados, tais como a melhora de sintomas ou a redução de tumores. Para doenças de grave ameaça à vida ou altamente debilitantes, como alguns tipos de câncer, a conclusão dessa fase pode ser suficiente para comprovação de eficácia e segurança da droga candidata. Nesses casos excepcionais, a Anvisa pode aceitar, para fins de registro, apenas os estudos de fase II concluídos, e os de fase III iniciados (quando aplicáveis), embora

${ }^{52}$ BRASIL. Ministério da Ciência e Tecnologia. Relatório de atividade do Grupo de Trabalho sobre a Fosfoetanolamina. Brasília, 22 dez 2015. Disponível em: <http://www.mcti.gov.br/ documents/10179/1274125/22-12-2015+-+Relat\%C3\%B3rio+de+Atividades+do+Grupo+de+Trabalho+ sobre+a+Fosfoetanolamina/d73d9f0f-16e8-4983-bce9-b5e57dfa2164>. Acesso em: 25 jun. 2016.

${ }^{53}$ BRASIL. Ministério da Ciência e Tecnologia. Resumo executivo. Avaliação da atividade citotóxica e antiproliferativa da Fosfoetanolamina, Monoetanolamina e Fosfobisetanolamina em Células Humanas de Carcinoma de Pâncreas e Melanoma, cit.

${ }^{54}$ INSTITUTO NACIONAL DE CÂNCER. Ações de enfermagem para o controle do câncer: uma proposta de integração ensino-serviço. Disponível em: <http://www.inca.gov.br/enfermagem/docs/cap7.pdf>. Acesso em: 14 fev. 2017.

${ }^{55}$ INTERNATIONAL MYELOMA FOUNDATION. Entendendo Estudos Clínicos. Disponível em: <http://www. myeloma.org.br/publicacao_download.php?file=estudos_clinicos.pdf>. Acesso em: 14 fev. 2017. 
geralmente seja exigida a conclusão dos estudos de fases I, II e III para solicitação do registro sanitário ${ }^{56,57}$.

Fase III: avalia o uso do medicamento em um grande número de pacientes (mínimo 800), muitas vezes envolvendo vários países. O objetivo é comparar o novo tratamento com o tratamento padrão existente, para estabelecer um benefício nessa relação. Nessa fase, espera-se obter maiores informações sobre segurança, eficácia e interação de drogas. Geralmente, os estudos dessa fase são randomizados, isto é, os pacientes são divididos em dois grupos, aleatoriamente: grupo controle (placebo ou tratamento padrão) e grupo investigacional (nova droga). Em pesquisa clínica de câncer, não é ético o uso de placebo; os pacientes utilizam um tratamento padrão e são acompanhados de perto nos centros de pesquisa (geralmente hospitais ou ambulatórios).

Fase IV: também conhecida como farmacovigilância. Nessa fase, o medicamento já foi registrado e já está sendo comercializado. Busca-se acompanhar, no longo prazo, mais detalhes sobre a eficácia e a segurança do medicamento, sendo que o principal objetivo é estabelecer novas reações adversas e confirmar a frequência de surgimento das já conhecidas. Trata-se do monitoramento do uso.

Os ensaios clínicos não foram comprovadamente realizados pelo grupo de Chierice ${ }^{58,59,60}$.

Diante da grande procura pela "pílula do câncer”, inúmeras reclamações foram feitas à Anvisa, que, então, decidiu publicar, em novembro de 2015, a Nota Técnica n. 56/SUMED/ANVISA, esclarecendo que até aquele momento não havia na agência nenhum pedido de registro da fosfoetanolamina sintética - como até hoje não há. Portanto, a agência não pode ser responsabilizada pela indisponibilidade da droga. Segundo as explicações dadas, um processo de registro de uma droga inovadora na Anvisa deve conter os relatórios de estudos pré-clínicos e clínicos (fases I, II e III) que comprovem que a droga candidata a medicamento tem segurança e eficácia, e possui benefícios em relação aos riscos. Além disso, o dossiê de registro deve ter dados comprobatórios da qualidade do produto e de seu prazo de

\footnotetext{
${ }^{56}$ AGÊNCIA NACIONAL DE VIGILÂNCIA SANITÁRIA. Resolução n. 60, de 10 de outubro de 2014. Dispõe sobre os critérios para a concessão renovação do registro de medicamentos com princípios ativos sintéticos e semissintéticos, classificados como novos, genéricos e similares, e dá outras providências. Disponível em: <http://bvsms.saude.gov.br/bvs/saudelegis/anvisa/2014/rdc0060_10_10_2014.pdf>. Acesso em: 17 maio 2017.

${ }^{57}$ INSTITUTO NACIONAL DE CÂNCER. Pesquisa clínica em câncer. Disponível em: <http://www2.inca.gov.br/ wps/wcm/connect/256e24804eb6939789f89bf11fae00ee/capa_rc12.pdf?MOD=AJPERES>. Acesso em: 15 fev. 2017.

${ }^{58}$ BRASIL. Ministério da Ciência e Tecnologia. Relatório de atividade do Grupo de Trabalho sobre a Fosfoetanolamina, cit.

${ }^{59}$ BRASIL. Ministério da Ciência e Tecnologia. Resumo executivo. Avaliação da atividade citotóxica e antiproliferativa da Fosfoetanolamina, Monoetanolamina e Fosfobisetanolamina em Células Humanas de Carcinoma de Pâncreas e Melanoma, cit.

${ }^{\circ}$ INTERNATIONAL MYELOMA FOUNDATION. Entendendo Estudos Clínicos, cit.
} 
validade, bem como a certificação de cumprimento de Boas Práticas de Fabricação da linha em que esse medicamento será fabricado e as autorizações sanitárias para o funcionamento da empresa ${ }^{61}$.

Em 2015, a divulgação de relatos de que muitas pessoas com câncer supostamente melhoravam com o uso das pílulas milagrosas foi aumentando. Por isso, milhares de pessoas com os mais diversos tipos de câncer procuravam a USP em busca da droga. A universidade passou a ser excessivamente demandada, principalmente por meio de liminares judiciais, sendo obrigada a manter a produção da droga - mesmo já estando aposentado o químico Gilberto Chierice, responsável pela fabricação e distribuição da droga, apesar de não possuir conhecimentos técnico-científicos para tanto. Assim, estava exercendo um papel que não o de uma universidade propriamente dita. Diante dessa insatisfação, a universidade decidiu entrar com ação no Tribunal de Justiça de São Paulo (TJ-SP), conseguindo encerrar a distribuição da droga em setembro de 2015, por decisão do presidente desse tribunal ${ }^{62,63}$.

Para Marco Antônio Zago, médico e reitor da USP, a autonomia da universidade estava sendo prejudicada. Disse ele: "Somos vistos como uma fábrica para produzir algo que nós não acreditamos que deve ser feito" ${ }^{4}$. Naquela época, a universidade divulgou uma nota esclarecedora sobre o assunto

Não existe demonstração cabal de que tenha ação efetiva contra a doença: a USP não desenvolveu estudos sobre a ação do produto nos seres vivos, muito menos estudos clínicos controlados em humanos. Não há registro e autorização de uso dessa substância pela Anvisa e, portanto, ela não pode ser classificada como medicamento, tanto que não tem bula ${ }^{65}$. (Destaques nossos.)

A suspensão do fornecimento durou até que o ministro Edson Fachin, do Supremo Tribunal Federal (STF), em decisão liminar de outubro de 2015, suspendeu

${ }^{61}$ AGÊNCIA NACIONAL DE VIGILÂNCIA SANITÁRIA. Nota Técnica n. 56/2015/SUMED/ANVISA. Esclarecimentos sobre a fosfoetanolamina. 2015. Disponível em: <http://portal.anvisa.gov.br/wps/wcm/connect/087adfO 04a38e24a8c7fcc4eff144ba1/NT_56_2015+SUMED+-+fosfoetanolamina.pdf?MOD=AJPERES>. Acesso em: 20 jun. 2016.

${ }^{62}$ LEDFORD, H. Nature. Brazilian courts tussle over unproven cancer treatment. Patients demand access to compound despite lack of clinical testing. Nature, International Weekly Journal of Science, 24 Nov. 2015. Disponível em: <http://www.nature.com/news/brazilian-courts-tussle-over-unproven-cancertreatment-1.18864>. Acesso em: 10 jun. 2016.

${ }^{63} \mathrm{MORSCH}, \mathrm{R}$. A judicialização da Fosfoetanolamina. Âmbito Jurídico, Rio Grande, v. 19, n. 144, jan. 2016. Disponível em: <http://ambitojuridico.com.br/site/?n_link=revista_artigos_leitura\&artigo_id=16699>. Acessoem: 23 jun. 2016.

${ }^{64}$ VARELLA, Gabriela. "Eu não gastaria R\$ 100 mil nessa pesquisa da fosfoetanolamina”, diz médico. Com edição de Marcela Buscato. Época, São Paulo, 19 out. 2015. Disponível em: <http://epoca.globo. $\mathrm{com} / \mathrm{vida} /$ noticia/2015/11/eu-nao-gastaria-r-100-mil-nessa-pesquisa-da-fosfoetanolamina-diz-medico. html>Acesso em: 29 jun. 2016.

${ }^{65} \mathrm{Id}$. Ibid. 
decisão do TJ-SP que impedia uma paciente de ter acesso à droga. Segundo o ministro, a decisão deu-se por se tratar de paciente em estado terminal, não sendo um precedente devido à excepcionalidade do caso. No entanto, após sua decisão, ações judiciais multiplicaram-se e a USP se viu sobrecarregada novamente. As decisões judiciais favoráveis ao fornecimento da fosfoetanolamina não observaram a recomendação n. 31/2010 do Conselho Nacional de Justiça, que orienta os magistrados de todo país a não autorizar o fornecimento de medicamentos ainda não registrados na Anvisa ou em fase experimental, ressalvadas as exceções previstas em lei ${ }^{66,67}$.

Também em outubro de 2015, as comissões de Ciência e Tecnologia e de Assuntos Sociais do Senado Federal realizaram uma Audiência Pública destinada a debater sobre a descoberta e o desenvolvimento de pesquisas com a fosfoetanolamina da USP. Ao final da reunião, o Ministério da Saúde, a Anvisa e o Ministério da Ciência e Tecnologia se comprometeram a dar total apoio ao desenvolvimento das pesquisas necessárias à comprovação da segurança e da eficácia dessa substância, de acordo com as exigências da legislação vigente. O MS, à época, recomendou que as pessoas não fizessem uso da fosfoetanolamina até que os estudos fossem concluídos. Para apoiar as etapas necessárias ao desenvolvimento clínico da fosfoetanolamina sintética, o MS instituiu um grupo de trabalho por meio da Portaria GM/MS n. $1.767 / 2015^{68}$.

Esse grupo de trabalho foi formado por representantes do Ministério da Saúde, do Instituto Nacional de Câncer (Inca), da Fiocruz, da Anvisa, do Ministério da Ciência e Tecnologia e do CNPq e por um pesquisador do Instituto Butantan (indicado pelo grupo de Chierice). Pesquisadores de renomados laboratórios Centro de Inovação e Ensaios Pré-Clínicos (CIENP), Laboratório de Avaliação e Síntese de Substâncias da Universidade Federal do Rio de Janeiro (LASSBio/UFRJ) e Núcleo de Pesquisa e Desenvolvimento de Medicamentos da Universidade Federal do Ceará (NPDM/UFC) - entraram também no grupo de discussão e, pouco tempo depois, foram convidados, juntamente com o Laboratório de Química Orgânica Sintética do Instituto de Química da Unicamp, pelo MCTI a desenvolver os estudos sobre a droga ${ }^{69}$.

Em novembro de 2015, o TJ-SP cassou todas as liminares de primeira instância que mandavam a USP fornecer a fosfoetanolamina sintética. Segundo o tribunal, é irresponsável liberar uma substância química que promete curar uma doença sem primar pelo rigor científico e sem constatação da eficácia. Os desembargadores também proibiram que juízes do estado tomassem decisões futuras com

\footnotetext{
${ }^{66}$ VARELLA, Gabriela. op. cit.

${ }^{67} \mathrm{MORSCH}$, R. op. cit.

${ }^{68}$ BRASIL. Ministério da Ciência e Tecnologia. Relatório de atividade do Grupo de Trabalho sobre a Fosfoetanolamina, cit.

${ }^{69}$ Id. Ibid.
} 
o mesmo tema. Isso trouxe alívio para a USP, embora a decisão só se aplicasse aos solicitantes da droga residentes no Estado de São Paulo, o que abrangia cerca de $80 \%$ das liminares recebidas para o composto ${ }^{70,71}$.

O MCTI divulgou um investimento de $\mathrm{R} \$ 10$ milhões nas etapas iniciais das pesquisas e atividades ligadas à fosfoetanolamina sintética, o que deixou muitos cientistas indignados - diante de um momento de crise, o governo financiava fortemente uma pesquisa que não era promissora, segundo os dados apresentados até aquele momento, enquanto outras pesquisas mais avançadas em câncer estavam tendo seu financiamento minado. O oncologista Carlos Ferreira, coordenador da Rede Nacional de Pesquisa Clínica em Câncer, é um dos cientistas que acreditam que outras pesquisas podem ser prejudicadas com isso. Em entrevista à revista Época ${ }^{72}$, disse: "Esses R 10 milhões serão retirados de algum lugar". Segundo ele, a judicialização foi o pior precedente disso tudo, pois qualquer indivíduo pode produzir algum produto e sair distribuindo, e, dependendo do tamanho da comoção social, um juiz pode autorizar o acesso ao produto. E acrescentou, "O problema é que o assunto saiu do âmbito da ciência e foi para o político. Isso é discutido dentro de comissões do Senado. Temo pela população, porque foi criada uma indústria de desespero". (Destaques nossos.)

Segundo o relatório do MCTI sobre a droga, desenvolvido pelo laboratório CIENP, o desempenho da droga foi muito inferior ao de outras drogas anticâncer já disponíveis há décadas. Esses resultados mostram que a fosfoetanolamina sintética produzida não é uma substância pura, e sim uma mistura de substâncias, contendo apenas $32 \%$ de fosfoetanolamina. O valor rotulado era de $500 \mathrm{mg}$, segundo alegava o grupo do químico Chierice, mas o peso real constatado em cada cápsula variava de $233 \mathrm{mg}$ a $368 \mathrm{mg}$, o que representa um imenso desvio de qualidade - algo impensável na fabricação de medicamentos ${ }^{73,74}$.

Ainda de acordo com o relatório do MCTI, a fosfoetanolamina sintética e a fosfoetanolamina nanoencapsulada - outro componente encontrado na cápsula não apresentaram ação tóxica em culturas de células tumorais e não tumorais, sendo que a fosfoetanolamina nanoencapsulada apresentou maior afinidade com as células tumorais. A fosfoetanolamina não apresentou ação antiproliferativa em

\footnotetext{
${ }^{70}$ LEDFORD, H. op. cit.

${ }^{71} \mathrm{MORSCH}$, R. op. cit.

${ }^{72}$ VARELLA, Gabriela. op. cit.

${ }^{73}$ ÁLVARES, D.; ALVES, G. Senado aprova 'pílula do câncer' após resultado negativo em teste. Folha de S. Paulo, 22 mar 2016. Disponível em: <http://www1.folha.uol.com.br/equilibrioesaude/2016/03/1752997senado-aprova-pilula-do-cancer-apos-resultado-negativo-em-teste.shtml>. Acesso em: 20 jun. 2016.

${ }^{74} \mathrm{MCTI}$ garante continuidade das pesquisas com a fosfoetanolamina. Ministério da Ciência, Tecnologia, Inovações e Comunicações, Notícias, 16 ago. 2016. Disponível em: <http://www.mcti.gov.br/ fosfoetanolamina-noticias/-/asset_publisher/QZohZ4pzYw5E/content/ministro-sugere-legalizarfosfoetanolamina-como-suplemento-alimentar;jsessionid=55CFCECE4D0C020CF8D66D8BB24AA2BA>. Acesso em: 29 jun. 2016.
} 
células tumorais de pâncreas e de melanoma. Apenas a monoetanolamina - outro componente encontrado nas cápsulas - apresentou atividade, embora essa atividade seja muito menos potente que a apresentada por duas substâncias já usadas em tratamento de câncer (cisplatina e gencitabina). Os únicos resultados positivos da cápsula pesquisada pelo grupo do CIENP contratado pelo MCTI foram a ausência de potencial de causar mutação genética em testes in vitro, e a ausência de toxicidade na dose máxima tolerada - ou seja, a droga não é tóxica, mesmo com ingestão em grande quantidade $\mathrm{e}^{75,76}$.

Em entrevista coletiva no final de março de 2016, Celso Pansera, então ministro da Ciência, Tecnologia e Inovação, sugeriu a legalização da fosfoetanolamina sintética como suplemento alimentar junto à Anvisa, por meio de uma solicitação a partir de um laboratório produtor. Para ele, a medida evitaria o mercado clandestino. Na ocasião, ele afirmou que, até aquele momento, já havia comprovação de não haver toxicidade no uso do composto em altas dosagens, como ocorria usualmente com as pessoas que usavam as pílulas quando estas eram distribuídas pelo grupo de Chierice. Esse uso era de três cápsulas por dia; como cada uma tinha, em média, $330 \mathrm{mg}$, o consumo equivalia a $1 \mathrm{~g}$ por $\mathrm{dia}^{77}$.

A medida sugerida pelo ministro à época não teve prosseguimento, mas não seria viável à luz da Lei n. 5.9991/197378, uma vez que a definição de medicamento, segundo essa lei, é de qualquer produto que alegue propriedades terapêuticas, independentemente de sua natureza (vegetal, animal, mineral ou sintética). A "pílula do câncer" reconhecidamente alegou tratar doença; portanto, tal droga não pode ser definida como alimento. Assim, é mais apropriado enquadrá-la como medicamento, à luz da legislação, mesmo que ainda faltem muitas etapas de estudos para que se possa chamá-la de medicamento. Ressalta-se que, para comercialização de qualquer medicamento, há o pré-requisito do registro na Anvisa, uma vez que Lei n. 6.360/1976, uma lei antiga, discorre que nenhum produto poderá ser industrializado, exposto à venda ou entregue ao consumo antes do registrado no órgão competente ${ }^{79}$.

Em março de 2016, a Câmara dos Deputados e, em seguida, o Senado Federal aprovaram, quase por unanimidade, o Projeto de Lei n. $4.639 / 2016^{80}$, que liberava a

\footnotetext{
${ }^{75}$ ÁLVARES, D.; ALVES, G. op. cit.

${ }^{76} \mathrm{MCTI}$ garante continuidade das pesquisas com a fosfoetanolamina, cit.

${ }^{77}$ MINISTRO sugere legalizar fosfoetanolamina como suplemento alimentar. Ministério da Ciência, Tecnologia, Inovações e Comunicações, Notícias, 30 mar. 2016. Disponível em: <http://www.mcti.gov.br/noticia/-/ asset_publisher/epbVOpr6elSO/content/ministro-sugere-legalizar-fosfoetanolamina-como-suplementoalimentar>. Acesso em: 30 jul. 2016.

${ }^{78}$ BRASIL. Lei n. 5.991, de 17 de dezembro de 1973.Dispõe sobre o Controle Sanitário do Comércio de Drogas, Medicamentos, Insumos Farmacêuticos e Correlatos, e dá outras Providências. Disponível em: <http://www.planalto.gov.br/ccivil_03/leis/L5991.htm>. Acesso em: 31 maio 2017.

${ }^{79}$ BRASIL. Lei n. 6.360, de 23 de setembro de 1976, cit.

${ }^{80}$ BRASIL. Câmara dos Deputados. Projeto de Lei n. 4639/2016. Dispõe sobre a fabricação, produção e distribuição da Fosfoetanolamina Sintética aos pacientes com câncer. Disponível em: <http://www.camara.gov. br/proposicoesWeb/fichadetramitacao?idProposicao=2025544>. Acesso em: 16 jun. 2016.
} 
"pílula do câncer". A tramitação em ambas as Casas foi extremamente rápida: 16 dias apenas. Na sessão de aprovação deste projeto de lei, os deputados fizeram discursos emocionados argumentando pela defesa da vida e citaram casos da doença em suas famílias, como se realmente a droga fosse a cura do câncer, ignorando que os estudos com a droga tivessem sido realizados apenas em animais (testes pré-clínicos) e que os resultados iniciais apenas revelaram a não toxicidade e a pouca eficácia do fármaco fosfoetanolamina sintética, segundo relatórios do MCTI.

A preocupação com a opinião pública predominou em relação aos fundamentos técnico-científicos, como é possível perceber pela fala do deputado Ronaldo Fonseca (PROS-DF):

Não vamos discutir a questão técnica. Isso não é para nós (...) a Câmara não pode ficar de costas para a opinião pública. Assim mostraremos à sociedade que a Câmara pensa, sim, no cidadão. Queremos plantar uma semente de esperança ${ }^{81}$. (Destaques nossos.)

No entanto, os parlamentares deveriam pensar que seus atos midiáticos podem levar a população a riscos, desmoralizando a autoridade sanitária do país. Pelo menos um deputado, Luiz Henrique Mandetta (DEM-MS), manifestou-se contrário ao projeto de lei, enfatizando a importância de tomar decisões com base na ciência, e não na emoção. Disse ele em plenário:

A maneira como se encaminha o tema é extremamente perigosa de fazer ciência [...]. Nós estamos reduzindo este debate a quem é a favor e contra a cura do câncer. A ciência é feita de pesquisa, de resultados. Não se pode liberar uma substância sem saber seu efeito colateral, qual é a dosagem para uma criança, para um idoso, para uma mulher ${ }^{82}$.

O deputado Ivo Cassol (PP-RO) fez um longo discurso, ao término da sessão de aprovação da Câmara, para agradecer o empenho dos colegas na aprovação da "pílula do câncer", que chamou de "descoberta do século", e completou dizendo que a droga ainda não havia passado por testes clínicos porque laboratórios e os oncologistas não tinham interesse em comercializá-la. Criticou a Anvisa e sua política de aprovação de medicamentos contra o câncer: "Do jeito que está, é uma vergonha nacional. Aprovou dois medicamentos que têm um efeito mínimo no tratamento de câncer, mas a um preço astronômico. Aí, sim, a Anvisa aprova”. Sua fala resulta de um total desconhecimento sobre o tema, pois a agência só registra um medicamento

\footnotetext{
${ }^{81}$ BARIFOUSE, R. Como a lei da 'pílula do câncer' uniu Congresso dividido e foi aprovada em tempo recorde. $B B C$ Brasil em São Paulo, maio 2016. Disponível em: <http://www.bbc.com/portuguese/brasil-36328587>. Acesso em: 03 jul. 2016.

${ }^{82}$ Id. Ibid.
} 
que tenha eficácia comprovada e benefício nítido em relação a outros medicamentos disponíveis no mercado ${ }^{83}$.

O Projeto de Lei n. 4.639/2016 ${ }^{84}$ seguiu para sanção presidencial e, em abril de 2016, transformou-se na Lei n. 13.269/2016 $6^{85}$. Esta autorizou a produção, a importação, a distribuição, a prescrição, a posse e o uso da substância, independentemente de registro sanitário e em caráter excepcional, por pacientes diagnosticados com neoplasia maligna, enquanto durarem os estudos clínicos do produto. O uso da fosfoetanolamina sintética ficou condicionado à apresentação de laudo médico que comprove o diagnóstico. Além disso, os pacientes devem assinar o termo de consentimento e responsabilidade ${ }^{86}$.

Apesar dos apelos da Anvisa, do Ministério do Desenvolvimento, Indústria e Comércio Exterior, do Ministério da Saúde, do MCTI, e da Advocacia-Geral da União, para que a então presidente da República, Dilma Rousseff, vetasse integralmente o Projeto de Lei n. 4.639/2016, ela sancionou na íntegra, sem vetos, a lei que liberava a droga. A motivação para esses órgãos serem contrários à liberação da fosfoetanolamina sintética por meio de lei é que isso poderia representar uma ameaça à saúde dos pacientes, além de abalar a imagem do controle sanitário do Brasil e, consequentemente, a imagem dos produtos vendidos no país ${ }^{87}$.

Inversamente, a Casa Civil posicionou-se a favor do Projeto de Lei, recomendando a sanção à presidente Dilma. Isso ocorreu devido a fortes pressões políticas que antecederam o momento do impeachment da presidente, que acabou acontecendo pouco tempo depois. O uso da droga foi liberado a pacientes, "por livre escolha", desde que tivessem laudo médico que comprovassem o diagnóstico, juntamente com termo de consentimento e responsabilidade assinado pelos próprios pacientes ou seus representantes legais ${ }^{88}$.

A Abrasco foi uma das instituições que incentivaram o veto presidencial. Seu entendimento é de que a autorização de medicamentos não é competência do Poder Legislativo, e sim dos órgãos de caráter técnico, como a Anvisa. Por isso, a associação escreveu uma Carta Aberta à Presidente da República ${ }^{89}$, solicitando o veto do Projeto de Lei n. 4.639/2016:

\footnotetext{
${ }^{83}$ BARIFOUSE, R. op. cit.

${ }^{84}$ BRASIL. Câmara dos Deputados. Projeto de Lei n. 4639/2016, cit.

${ }^{85}$ BRASIL. Lei $n$. 13.296, de 13 de abril de 2016, cit.

${ }^{86}$ ÁLVARES, D.; ALVES, G. op. cit.

${ }^{87}$ DILMA sanciona lei que autoriza o uso da ‘pílula do câncer', sem vetos. Correio Brasiliense, 14 abril 2016. Disponível em: <http://www.correiobraziliense.com.br/app/noticia/brasil/2016/04/14/internas_polbraeco,527244/ dilma-sanciona-lei-que-autoriza-o-uso-da-pilula-do-cancer-sem-vetos.shtml>. Acesso em: 14 jun. 2016.

${ }^{88}$ Id. Ibid.

${ }^{89}$ REIS, V. Fosfoetanolamina sintética: Carta Aberta da Abrasco para reivindicar veto ao Projeto de Lei 4639/16. Abrasco. Associação Brasileira de Saúde Coletiva, 06 abr. 2016. Disponível em: <https://www. abrasco.org.br/site/2016/04/fosfoetanolamina-sintetica-carta-aberta-da-abrasco-para-reivindicar-vetoao-projeto-de-lei-463916/>. Acesso em: 8 jun. 2016.
} 
A Associação Brasileira de Saúde Coletiva ABRASCO dirige-se respeitosamente a Vossa Excelência para reivindicar vosso veto ao Projeto de Lei 4639/16, que autoriza a produção e o uso da fosfoetanolamina sintética como medicamento. O mencionado PL foi aprovado pela Câmara e pelo Senado, nos dias 8 e 23 de março últimos, respectivamente, e aguarda sanção ou veto da Presidência da República.

A autorização de medicamentos não compete ao Poder Legislativo e à Presidência da República. Nas sociedades contemporâneas, esse tipo de decisão compete a órgãos técnicos; no Brasil, é atribuição da Agência Nacional de Vigilância Sanitária - ANVISA, segundo a Lei $\mathrm{n}^{\circ} 9.782$, de 26/01/1999. A determinação da segurança e da eficácia de um medicamento depende dos resultados de uma sequência de estudos clínicos cujos métodos e protocolos já se encontram consolidados pela comunidade cientifica. Não se dispõe ainda de resultados desses estudos no caso da fosfoetanolamina sintética.

Em respeito às atribuições legais da ANVISA, e aos melhores interesses de proteção à saúde dos brasileiros, reiteramos a importância do veto presidencial ao PL 4639/16.

Respeitosamente, Gastão Wagner de Sousa Campos Presidente da Associação Brasileira de Saúde Coletiva - Abrasco. (Destaques nossos.)

Para Jarbas Barbosa, atual diretor presidente da Anvisa, os riscos representados pela Lei n. 13.269/2016 são tremendos, por colocar a fosfoetanolamina sintética fora do ambiente regulatório brasileiro, que vinha sendo construído desde 1970 e culminou, em 1999, na criação da agência. A droga seria comercializada sem número de registro, sem número de lote e sem data de fabricação. Isso, segundo Jarbas, prejudicaria a fiscalização. Há uma regra de excepcionalidade para autorizar um medicamento quando ele é promissor, mas a fosfoetanolamina não se enquadra nela porque não é um medicamento - ela só tem relatos individuais de pessoas se sentindo melhor, podendo ser apenas um placebo. Para ele, a imagem da Anvisa não ficou abalada, mas sim a imagem do país como um todo, já que internacionalmente é visto como um país que possui atalhos no Judiciário e no Legislativo para autorizar medicamentos sem considerar a análise do órgão técnico responsável.

Eu tenho o maior respeito pelo Congresso Nacional, mas ele não é capaz de fazer uma análise técnica. E a autorização de um medicamento tem que ser feita por meio de uma análise técnica com base na ciência e em informações. O Congresso tem uma visão política porque é um órgão político. É por isso que, em nenhum lugar civilizado e em nenhum país desenvolvido, é o 
Congresso Nacional quem autoriza o uso do medicamentos, afirmou Jarbas Barbosa ${ }^{90,91}$. (Destaques nossos.)

Outra associação contrária à sanção da Lei n. 13.269/2016 foi a Associação Médica Brasileira (AMB), que ajuizou no STF a Ação Direta de Inconstitucionalidade (ADI) 5501, alegando a ausência de testes da substância em seres humanos e o desconhecimento acerca da eficácia e dos possíveis efeitos colaterais do medicamento. A AMB alegou também que a Lei n. 13.269/2016 viola direitos constitucionais fundamentais, tais como o direito à saúde (artigos $6^{\circ}$ e 196), o direito à segurança e à vida (artigo $5^{\circ}$, caput) e o princípio da dignidade da pessoa humana $\left(\operatorname{artigo} 1^{\circ} \text {, inciso III }\right)^{92}$.

Em maio de 2016, ao analisar a ADI 5501, o STF suspendeu a eficácia da Lei n. 13.269/2016 por maioria dos votos (6 versus 4). Com a referida decisão, a lei ficará suspensa até o julgamento definitivo da ação. O relator da medida cautelar, ministro Marco Aurélio, foi favorável ao deferimento da liminar. Para ele, o dever do Estado de fornecer medicamentos à população contrapõe-se à responsabilidade constitucional de zelar pela qualidade e segurança dos produtos em circulação. Em seu voto, disse:

Ao suspender a exigibilidade de registro sanitário da fosfoetanolamina sintética, o ato atacado discrepa das balizas constitucionais concernentes ao dever estatal de reduzir o risco de doença e outros agravos à saúde dos cidadãos ${ }^{93}$. (Destaques nossos.)

Segundo o ministro, o Congresso Nacional não cumpriu com o dever constitucional de tutela da saúde da população, ao possibilitar a distribuição de um medicamento sem o controle sanitário prévio da Anvisa e visto que o Estado deve concretizar o direito à saúde ao assegurar a qualidade das drogas distribuídas aos indivíduos, mediante rigoroso crivo científico, apto a afastar desenganos, charlatanismos e efeitos prejudiciais ao ser humano ${ }^{94}$.

\footnotetext{
${ }^{90} \mathrm{CANCIAN}, \mathrm{N}$. Caso como o da ‘pílula do câncer' prejudica o país, diz diretor da Anvisa. Folha de São Paulo, maio 2016. Disponível em: <http://www1.folha.uol.com.br/cotidiano/2016/05/1766592-caso-como-oda-pilula-do-cancer-prejudica-o-pais-diz-diretor-da-anvisa.shtml>. Acesso em: 30 jun. 2016.

${ }^{91} \mathrm{LEAL}$, Anita; LABOISSIÈRE, Paula. Anvisa: lei que autoriza uso da fosfoetanolamina pode colocar população em risco. EBC Agência Brasil, 14 abr. 2016. Disponível em: <http://agenciabrasil.ebc.com.br/geral/ noticia/2016-04/anvisa-lei-que-autoriza-uso-da-fosfoetanolamina-pode-colocar-populacao-em>. Acesso em: 16 jun. 2016.

${ }^{92} \mathrm{AMB}$ questiona lei que libera uso da fosfoetanolamina sintética. 2016. Notícias STF, 16 abr. 2016. Disponível em: <http://www.stf.jus.br/portal/cms/verNoticiaDetalhe.asp?idConteudo=314574\&caixaBus $\mathrm{ca}=\mathrm{N}>$. Acesso em: 16 jun. 2016.

${ }^{93}$ STF suspende eficácia da lei que autoriza uso da fosfoetanolamina. Notícias STF, 19 maio 2016. Disponível em: <http://www.stf.jus.br/portal/cms/verNoticiaDetalhe.asp?idConteudo=317011>. Acesso em: 16 jun. 2016.

${ }^{94}$ Id. Ibid.
} 
Afirmou que: "Ante a ausência do registro, a inadequação é presumida". Haja vista que a aprovação de um medicamento pela Anvisa é condição para industrialização, comercialização e importação com fins comerciais, segundo o artigo 12 da Lei n. 6.360/1976. Além disso, não cabe ao Congresso Nacional viabilizar a distribuição de qualquer medicamento, mas sim à Anvisa. Sendo assim, esse episódio é uma ofensa ao postulado da separação de Poderes. O relator concluiu:

É no mínimo temerária - e potencialmente danosa - a liberação genérica do medicamento sem a realização dos estudos clínicos correspondentes, em razão da ausência, até o momento, de elementos técnicos assertivos da viabilidade da substância para o bem-estar do organismo humano. Salta aos olhos, portanto, a presença dos requisitos para o implemento da medida acauteladora $^{95}$. (Destaques nossos.)

O ministro Luís Roberto Barroso acompanhou o relator em seu voto. Afirmou que os testes que comprovariam que a fosfoetanolamina sintética é um composto seguro e eficaz deveriam ser anteriores à autorização de uso; caso contrário, a saúde, o bem-estar e a vida das pessoas estariam em risco, sendo uma afronta ao direito à saúde. $\mathrm{O}$ referido ministro entende o caso como uma violação à reserva de administração, pois há uma exigência legal de realização de testes clínicos e de registro sanitário necessariamente anterior à liberação do uso da fosfoetanolamina. Disse em seu voto, "O Poder Legislativo substitui o juízo essencialmente técnico da Anvisa por um juízo político, interferindo de forma indevida em procedimento de natureza tipicamente administrativo $0^{96}$.

O ministro Teori Zavascki também foi a favor da concessão à liminar, por concordar com a alegação de inconstitucionalidade pelo fato de a atividade em questão pertencer ao Poder Executivo: "É certo que o legislador pode disciplinar a matéria. O Sistema Único de Saúde (SUS) atua nos termos da lei. Todavia, não parece constitucionalmente legítimo que o legislador, além de legislar, assuma para si uma atividade tipicamente executiva" 97. (Destaques nossos.)

Consoante com o relator votou também o ministro Luiz Fux. Alegou que o uso da fosfoetanolamina pode favorecer o abandono de tratamentos usuais da doença. De acordo com ele, observa-se um perigo, já que não se podem mensurar as consequências do uso dessa substância, com possível violação ao direito à saúde e a uma vida digna ${ }^{98}$.

\footnotetext{
${ }^{95}$ STF suspende eficácia da lei que autoriza uso da fosfoetanolamina, cit.

${ }^{96}$ Id. Ibid.

${ }^{97}$ Id. Ibid,

${ }^{98}$ Id. Ibid.
} 
A ministra Cármen Lúcia também acompanhou o relator. Para ela, os médicos são unânimes no sentido de que há riscos na utilização do composto e alegam que ainda não se conhecem seus efeitos colaterais. Justificou seu voto dizendo: "Para que não se veja na pílula do câncer mais uma pílula de engano para quem já está sofrendo com o desengano". Mencionou também em sua fala a RDC n. 38/2013 ${ }^{99}$ da Anvisa. Essa RDC prevê três programas para fornecimento de medicamento novo e promissor, mas ainda sem registro, aos pacientes vítimas de doenças raras, debilitantes e graves, quando outros produtos com registro não forem alternativas satisfatórias ao tratamento. Para tanto, cabe à Anvisa a anuência de quais indivíduos podem participar desses programas e, assim, terem acesso aos medicamentos ainda sem registro.

Acho que a interpretação conforme a Constituição liberaria de forma ampla e geral [o uso da substância] e sem os cuidados previstos pela Resolução n. 38, da Anvisa, que estabelece como um dever da própria agência a verificação de quais pacientes podem se submeter ao uso desse medicamento ${ }^{100}$. (Destaques nossos.)

O presidente do STF, ministro Ricardo Lewandowski, votou conforme a maioria, concordando com o deferimento da liminar. Para ele, permitir ao Parlamento legislar na área da farmacologia abre um precedente "extremamente perigoso" (destaques nossos), colocando em risco a saúde da população. Segundo seus dizeres,

Não me parece admissível que hoje o Estado - sobretudo no campo tão sensível que é o campo da saúde, que diz respeito à vida e à dignidade da pessoa - possa agir irracionalmente, levando em conta razões de ordem metafísica ou fundado em suposições que não tenham base em evidências científicas ${ }^{101}$. (Destaques nossos.)

\section{Conclusão}

Este trabalho buscou, primeiramente, demonstrar a importância da Anvisa em seu fundamental papel para a saúde pública brasileira. Depois tratou sobre as tentativas do Poder Legislativo federal, especialmente a Câmara dos Deputados, de proibir a Anvisa de exercer sua função de controle sanitário de medicamentos inibidores de apetite e, por fim, o disparate da liberação por lei da fosfoetanolamina

\footnotetext{
${ }^{99}$ AGÊNCIA NACIONAL DE VIGILÂNCIA SANITÁRIA. Resolução n. 38, de 12 de agosto de 2013. Aprova o regulamento para os programas de acesso expandido, uso compassivo e fornecimento de medicamento pós-estudo. Disponivel em: <http://www.sbppc.org.br/site/images/publicacoes/dou\%20-\%20resolu\%E7\%E3o\%20rdc\%20 38_\%20de\%2012\%20de\%20agosto\%20de\%202013.pdf>. Acesso em: 31 maio. 2017.

${ }^{100}$ STF suspende eficácia da lei que autoriza uso da fosfoetanolamina, cit.

${ }^{101}$ Id. Ibid.
} 
sintética, tida como medicamento e sem passar por estudos pré-clínicos completos, estudos clínicos e outros testes que assegurassem a eficácia, a segurança e a qualidade, ignorando-se a obrigatoriedade do registro sanitário pelo órgão responsável e tecnicamente competente.

No decorrer do trabalho, pode-se perceber que boa parte da comunidade científica, associações, como a Abrasco, autoridades como Agenor Álvares, Geraldo Lucchese, Jarbas Barbosa, ministros do STF e até mesmo alguns parlamentares são contrários às recentes ofensas que a vigilância sanitária do país vem sofrendo, mesmo sendo uma área valorizada pela CF/88 e por outras leis - como a Lei n. 9.782/1999, que criou e concedeu o poder regulatório à Anvisa. Contraditoriamente, a Lei n. 9.782/1999 foi editada pelo Legislativo federal, que está constantemente ameaçando as competências da agência.

Apesar de ser uma instituição com a finalidade nobre de proteger a saúde da população e de ser reconhecida como confiável, nacional e internacionalmente, a Anvisa está sendo desmoralizada, tendo sua capacidade regulatória tolhida por pressões sociais e políticas. É lamentável saber que muitos parlamentares, que deveriam representar o povo, estão priorizando interesses de grupos poderosos ou cedendo à pressão popular, em vez de prezar pelo conhecimento científico consolidado e pela segurança sanitária do País, ariscando, assim, a saúde da população.

Cabe à Anvisa continuar alertando a sociedade quanto aos riscos do consumo inconsequente de certos produtos, autorizados por caminhos alternativos sem passar por seu crivo técnico-científico, uma vez que seu papel é tentar minimizar os possíveis danos desse uso. Compete também à agência defender sua função e autonomia institucional frente à sociedade e a outros poderes do Estado, que muitas vezes desacreditam sua atuação, seja por meio da judicialização irresponsável, seja pela elaboração de leis descabidas que afrontam suas competências.

\section{Referências}

AGÊNCIA NACIONAL DE VIGILÂNCIA SANITÁRIA. Nota Técnica

n. 56/2015/SUMED/ANVISA. Esclarecimentos sobre a fosfoetanolamina. 2015. Disponível em: <http://portal.anvisa.gov.br/wps/wcm/connect/087adf004a38e24a8c7fcc4eff144ba1/ NT_56_2015+SUMED+-+fosfoetanolamina.pdf?MOD=AJPERES>. Acesso em: 20 jun. 2016.

. Nota Técnica sobre a eficácia e segurança dos medicamentos inibidores de apetite. Brasília, 2011. Disponível em: <http://www.anvisa.gov.br/hotsite/anorexigenos/pdf/Nota_ Tecnica_Anorexigenos.pdf>. Acesso em: 16 jun. 2016.

ALMEIDA, E. S.; XAVIER, E. D. O poder normativo e regulador das agências reguladoras federais: abrangência e limites. Âmbito Jurídico, Rio Grande, v. 15, n. 98, mar. 2012. Disponível em: <http://www.ambitojuridico.com.br/site/?artigo_id=11293\&n_ link=revista_artigos_leitura $>$. Acesso em: 15 jun. 2016. 
ÁLVARES, D.; ALVES, G. Senado aprova 〈pílula do câncer〉 após resultado negativo em teste. Folha de S. Paulo, 22 mar 2016. Disponível em: <http://www1.folha.uol.com.br/ equilibrioesaude/2016/03/1752997-senado-aprova-pilula-do-cancer-apos-resultadonegativo-em-teste.shtml>. Acesso em: 20 jun. 2016.

AMB questiona lei que libera uso da fosfoetanolamina sintética. 2016. Notícias STF, 16 abr. 2016. Disponível em: <http://www.stf.jus.br/portal/cms/verNoticiaDetalhe.asp?idConteud $\mathrm{o}=314574 \&$ caixaBusca $=\mathrm{N}>$. Acesso em: 16 jun. 2016.

ANOREXÍGENOS: posição da Anvisa sobre o PLC 61/15. Agência Nacional de Vigilância Sanitária - ANVISA, 22 abr. 2016. Disponível em: <http://portal.anvisa.gov.br/ noticias?p_p_id=101_INSTANCE_FXrpx9qY7FbU\&p_p_col_id=column2\&p_p_col_ pos=1\&p_p_col_count=2\&_101_INSTANCE_FXrpx9qY7FbU_groupId=219201\&_101_ INSTANCE_FXrpx9qY7FbU_urlTitle=anvisa-manifesta-preocupacao-pelos-possiveisresultados-da-aprovacao-do-plc-61-15\&_101_INSTANCE_FXrpx9qY7FbU_struts_ action=\%2Fasset_publisher\%2Fview_content\&_101_INSTANCE_FXrpx9qY7FbU_ assetEntryId=2657060\&_101_INSTANCE_FXrpx9qY7FbU_type=content $>$. Acesso em: 28 jun. 2016.

ANVISA requer novo registro para comercialização de mazindol, femproporex e anfepramona. Notícias, Conselho Regional de Farmácia de Estado de São Paulo - CRF SP, São Paulo, 26 set. 2014. Disponível em: <http://portal.crfsp.org.br/index.php/ noticias/5862-rdc-50-14.html>. Acesso em: 26 jun. 2016.

ASSOCIAÇÃO BRASILEIRA DE SAÚDE COLETIVA. Carta Aberta ao Congresso Nacional contra a aprovação do projeto de Lei $n^{\circ} 2.431 / 2011$. A regulação dos anorexígenos no Brasil. dez 2013. Disponível em: <https://www.abrasco.org. $\mathrm{br} /$ site/2013/12/carta-aberta-ao-congresso-nacional-contra-a-aprovacaodo-projeto-de-lei-no-2-4312011-a-regulacao-dos-anorexigenos-no-brasil/>. Acesso em: 20 jun. 2016.

BARIFOUSE, R. Como a lei da 'pílula do câncer' uniu Congresso dividido e foi aprovada em tempo recorde. BBC Brasil em São Paulo, maio 2016. Disponível em: <http://www.bbc. com/portuguese/brasil-36328587>. Acesso em: 03 jul. 2016.

BRASIL. Câmara dos Deputados. Comissão de Seguridade Social e Família. Relatório final do Grupo de Trabalho destinado a acompanhar e discutir a Nota Técnica da Anvisa, que prevê o banimento dos medicamentos inibidores de apetite. Brasília, nov. 2011. Disponível em: <http://www2.camara.leg.br/atividade-legislativa/comissoes/comissoes-permanentes/ cssf/documentos-1/relatorios-2/relatorio-do-grupo-de-trabalho-medicamentosinibidoresde-apetite>. Acesso em: 25 jun. 2016.

. Ministério da Ciência e Tecnologia. Relatório de atividade do Grupo de Trabalho sobre a Fosfoetanolamina. Brasília, $22 \mathrm{dez} 2015$. Disponível em: <http://www.mcti.gov.br/ documents/10179/1274125/22-12-2015+-+Relat\%C3\%B3rio+de+Atividades+do+Grup o+de+Trabalho+sobre+a+Fosfoetanolamina/d73d9f0f-16e8-4983-bce9-b5e57dfa2164>. Acesso em: 25 jun. 2016. 
BRASIL. Ministério da Ciência e Tecnologia. Resumo executivo. Avaliação da atividade citotóxica e antiproliferativa da Fosfoetanolamina, Monoetanolamina e Fosfobisetanolamina em Células Humanas de Carcinoma de Pâncreas e Melanoma. Abr. 2016. Disponível em: <http://www.mcti.gov.br/documents/10179/1274125/ Resumo+executivo+Encomenda+MCTI-CNPq+-+Citoxicidade+celulas + canceriginas $+\mathrm{h}$ umanas.pdf/b1acdfa5-4743-4bfe-affa-0e8ca222fad2>. Acesso em: 29 jul. 2016.

Senado Federal. Comissões. 16 fev. 2016. Disponível em: <http://www12. senado.leg.br/noticias/materias/2016/02/16/venda-de-remedios-para-emagrecer-podeserautorizada-por-lei/tablet>. Acesso em: 26 jun. 2016.

CÂMARA aprova urgência para projeto que ratifica liberação de inibidores de apetite. Resolução da Anvisa que proibia a venda desses medicamentos já foi derrubada pelo Congresso em 2014. Câmara Notícias, Brasília, 14 jun. 2016. Disponível em: <http:// www2.camara.leg.br/camaranoticias/noticias/SAUDE/510594-CAMARA-APROVAURGENCIA-PARA-PROJETO-QUE-RATIFICA-LIBERACAO-DE-INIBIDORES-DEAPETITE.html>Acesso em: 25 jun. 2016.

CANCIAN, N. Caso como o da 'pílula do câncer' prejudica o país, diz diretor da Anvisa. Folha de São Paulo, maio 2016. Disponível em: <http://www1.folha.uol.com.br/ cotidiano/2016/05/1766592-caso-como-o-da-pilula-do-cancer-prejudica-o-pais-dizdiretor-da-anvisa.shtml>. Acesso em: 30 jun. 2016.

COSTA, E. A. Regulação e vigilância sanitária para a proteção da saúde. In: Vieira, F. P.; Rediguieri, C. F.; Rediguieri, C. F. (Orgs.). A regulação de medicamentos no Brasil. Porto Alegre: Artmed, 2013. p. 21-37.

DIAS, Bruno C. Decreto aprovado pela Câmara dos Deputados libera venda e produção de anorexígenos. ABRASCO. Associação Brasileira de Saúde Coletiva, 09 abr. 2014. Disponível em: <https://www.abrasco.org.br/site/2014/04/decreto-aprovado-pela-camara-dosdeputados-libera-venda-e-producao-de-anorexigenos-coordenacao-do-gt-visa-lancanota-de-repudio/>. Acesso em: 24 jun. 2016.

DILMA sanciona lei que autoriza o uso da 'pílula do câncer', sem vetos. Correio Brasiliense, 14 abril 2016. Disponível em: <http://www.correiobraziliense.com.br/app/noticia/ brasil/2016/04/14/internas_polbraeco,527244/dilma-sanciona-lei-que-autoriza-o-uso-dapilula-do-cancer-sem-vetos.shtml>. Acesso em: 14 jun. 2016.

FACHIN fala sobre a decisão de liberar a Fosfoetanolamina: "Foi uma exceção." Época, São Paulo, 19 out. 2015. Disponível em: <http://epoca.globo.com/tempo/filtro/ noticia/2015/10/fachin-fala-sobre-decisao-de-liberar-fosfoetanolamina-foi-uma-excecao. html>. Acesso em: 26 jun. 2016.

INSTITUTO NACIONAL DE CÂNCER. Ações de enfermagem para o controle do câncer: uma proposta de integração ensino-serviço. Disponível em: <http://www.inca.gov.br/ enfermagem/docs/cap7.pdf >. Acesso em: 14 fev. 2017. 
INSTITUTO NACIONAL DE CANCER. Pesquisa clínica em câncer. Disponível em: $<$ http://www2.inca.gov.br/wps/wcm/connect/256e24804eb6939789f89bf11fae00ee/capa rc12.pdf?MOD=AJPERES $>$. Acesso em: 15 fev. 2017.

INTERNATIONAL MYELOMA FOUNDATION. Entendendo Estudos Clínicos. Disponível em: <http://www.myeloma.org.br/publicacao_download.php?file=estudos_clinicos.pdf $>$. Acesso em: 14 fev. 2017.

LEAL, Anita; LABOISSIÈRE, Paula. Anvisa: lei que autoriza uso da fosfoetanolamina pode colocar população em risco. EBC Agência Brasil, 14 abr. 2016. Disponível em: $<$ http://agenciabrasil.ebc.com.br/geral/noticia/2016-04/anvisa-lei-que-autoriza-uso-dafosfoetanolamina-pode-colocar-populacao-em>. Acesso em: 16 jun. 2016.

LEDFORD, H. Nature. Brazilian courts tussle over unproven cancer treatment. Patients demand access to compound despite lack of clinical testing. Nature, International Weekly Journal of Science, 24 Nov. 2015. Disponível em: <http://www.nature.com/news/braziliancourts-tussle-over-unproven-cancer-treatment-1.18864>. Acesso em: 10 jun. 2016.

LUCCHESE, Geraldo. Projeto de Lei no 2.431, de 2011, e a regulação dos anorexígenos no Brasil. Escola Nacional de Saúde Pública Sérgio Arouca - Fundação Oswaldo Cruz, 2013. Disponível em: <http://www6.ensp.fiocruz.br/visa/?q=node/5910>Acesso em: 25 jun. 2016.

MCTI garante continuidade das pesquisas com a fosfoetanolamina. Ministério da Ciência, Tecnologia, Inovações e Comunicações, Notícias, 16 ago. 2016. Disponível em: <http:// www.mcti.gov.br/fosfoetanolamina-noticias/-/asset_publisher/QZohZ4pzYw5E/content/ ministro-sugere-legalizar-fosfoetanolamina-como-suplemento-alimentar;jsessionid $=55 \mathrm{CF}$ CECE4D0C020CF8D66D8BB24AA2BA>. Acesso em: 29 jun. 2016.

MINISTRO sugere legalizar fosfoetanolamina como suplemento alimentar. Ministério da Ciência, Tecnologia, Inovações e Comunicações, Notícias, 30 mar. 2016. Disponível em: <http://www.mcti.gov.br/noticia/-/asset_publisher/epbV0pr6eIS0/content/ ministro-sugere-legalizar-fosfoetanolamina-como-suplemento-alimentar $>$. Acesso em: 30 jul. 2016.

MORSCH, R. A judicialização da Fosfoetanolamina. Âmbito Jurídico, Rio Grande, v. 19, n. 144, jan. 2016. Disponível em: <http://ambitojuridico.com.br/site/?n_link=revista_ artigos_leitura\&artigo_id=16699>. Acessoem: 23 jun. 2016.

"PODEMOS comemorar a inserção da Vigilância Sanitária como uma parte da saúde coletiva”. Entrevistado: José Agenor Álvares da Silva. Escola Nacional de Saúde Pública Sérgio Arouca - Fundação Oswaldo Cruz, 16 jun. 2014. Disponível em: <http://www6.ensp. fiocruz.br/visa/?q=node/6170>. Acesso em: 14 jun. 2016.

REIS, V. Fosfoetanolamina sintética: Carta Aberta da Abrasco para reivindicar veto ao Projeto de Lei 4639/16. Abrasco. Associação Brasileira de Saúde Coletiva, 06 abr. 2016. Disponível em: <https://www.abrasco.org.br/site/2016/04/fosfoetanolamina-sintetica-cartaaberta-da-abrasco-para-reivindicar-veto-ao-projeto-de-lei-463916/>. Acesso em: 8 jun. 2016. 
STF suspende eficácia da lei que autoriza uso da fosfoetanolamina. Notícias STF, 19 maio 2016. Disponível em: <http://www.stf.jus.br/portal/cms/verNoticiaDetalhe. asp?idConteudo=317011>. Acesso em: 16 jun. 2016.

VARELLA, Gabriela. “Eu não gastaria R\$ 100 mil nessa pesquisa da fosfoetanolamina”, diz médico. Com edição de Marcela Buscato. Época, São Paulo, 19 out. 2015. Disponível em: $<$ http://epoca.globo.com/vida/noticia/2015/11/eu-nao-gastaria-r-100-mil-nessa-pesquisada-fosfoetanolamina-diz-medico.html>Acesso em: 29 jun. 2016.

Ana Carolina Perdigão Faleiros - Especialista em Vigilância Sanitária pela Pontifícia Universidade Católica de Goiás; graduada em Ciências Farmacêutica pela Universidade de Brasília. Especialista em Regulação e Vigilância Sanitária na Agência Nacional de Vigilância Sanitária. Brasília/DF, Brasil. E-mail: ana.faleiros@anvisa.gov.br. 